\title{
Integrating epidemiological and engineering approaches in the assessment of human casualties in earthquakes
}

\author{
Stav Shapira ${ }^{1,2} \cdot$ Limor Aharonson-Daniel ${ }^{1,2} \cdot$ \\ Igal M. Shohet ${ }^{3}$. Corinne Peek-Asa ${ }^{4}$. \\ Yaron Bar-Dayan ${ }^{1,2}$
}

Received: 19 August 2014/ Accepted: 20 April 2015/Published online: 5 May 2015

(C) The Author(s) 2015. This article is published with open access at Springerlink.com

\begin{abstract}
Earthquakes pose substantial risks of human health. Preparedness and mitigation strategies can reduce earthquake-related injuries and deaths and information from casualty models that predict earthquake outcomes can help communities prepare. This study identifies epidemiologic and medical risk factors for earthquake casualties, and compares them with engineering casualty models for the purpose of providing evidence that integrates these approaches. It aims to improve earthquake casualty modeling and to offer better accurate estimations. Epidemiological studies that used analytical designs and reported risk factors related to earthquake-induced casualties and studies that examined the association between medical preparedness and earthquake-induced casualties were reviewed. Engineering casualty estimation models were reviewed to identify which risk factors were considered in the models. Epidemiological studies identified the following risk factors: gender, age, socioeconomic status, physical disability and human behavior. Medical preparedness factors were also related to earthquake-induced injury and death. Global casualty estimation models do not currently consider these factors. This study provides evidence that integrating demographic and socioeconomic characteristics of the population and levels of medical preparedness into the existing casualty estimation models may improve their accuracy.
\end{abstract}

Stav Shapira

stav.shapira@gmail.com

1 Department of Emergency Medicine, Leon and Mathilde Recanati School for Community Health Professions, Faculty of Health Sciences, Ben-Gurion University of the Negev, P.O. Box 653, 84105 Beer-sheva, Israel

2 PREPARED Center for Emergency Response Research, Ben-Gurion University of the Negev, P.O. Box 653, 84105 Beer-sheva, Israel

3 Department of Structural Engineering, Faculty of Engineering Sciences, Ben-Gurion University of the Negev, P.O. Box 653, 84105 Beer-sheva, Israel

4 Department of Occupational and Environmental Health, University of Iowa, Iowa City, IO, USA 
Keywords Earthquakes - Mass casualty incidents - Risk assessment - Socioeconomic factors $\cdot$ Disaster planning

\section{Introduction}

The estimated number of casualties is one of the central factors guiding emergency preparedness planning for a strong earthquake. The casualty burden from massive earthquakes is high. Earthquakes were the most deadly natural disaster in the last 24 years, resulting in over 800,000 deaths and 1.7 million injuries (46\% of the total death toll and $29 \%$ of total injuries caused by natural disasters from 1990 to 2013) (EM-DAT 2014). Global trends toward urbanization combined with an increase in population density, poverty and social gaps increase the vulnerability of urban centers in the face of natural disasters, including earthquakes (Tekeli-Yesil 2006; Donner and Rodriguez 2008). Casualty modeling has traditionally been conducted using engineering methods, which focus only on damage to the built environment. Thus, the major source of information for community preparedness activities does not consider the exposed population and has rarely integrated human factors.

Several studies have examined the association of earthquake casualties with various seismic factors such as the magnitude of the earthquake (Alexander 1985; Samadjieva and Badel 2002), ground motion parameters such as peak ground acceleration (Shoaf et al. 1998; Mahue-Giangreco et al. 2001), shaking intensity and distance from epicenter (Liang et al. 2001). These factors do not account for the wide variations in earthquake casualties.

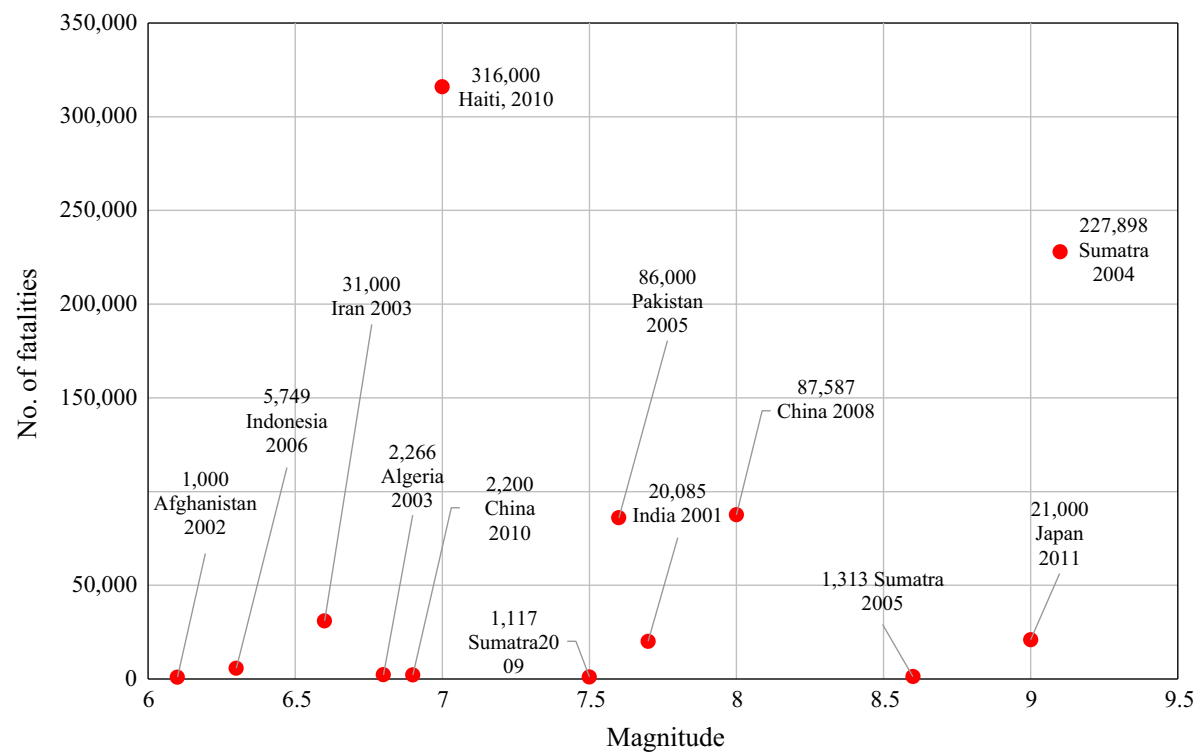

Fig. 1 Fatal earthquakes (over 1000 fatalities) since the year 2000 (the figure is based on data from the USGS website) 
For example, magnitude is not strongly associated with the number of casualties in each event.

Based on existing studies, damage to buildings is considered the most important factor causing injury and death in earthquake events worldwide (Jaiswal et al. 2009; Peek-Asa et al. 1998; Noji and Kelen 1990; Spence et al. 2003; Wald et al. 2011; Porter et al. 2008; Jaiswal et al. 2009). Countries such as Japan and New Zealand, which have implemented strict seismic building codes and invested resources to enhance community preparedness, have demonstrated a dramatic decrease in the number of earthquake casualties compared to other developed countries such as China, India or Haiti, which still present high vulnerability to earthquakes (Paton et al. 2010; Crowley and Elliott 2012). This is demonstrated in Fig. 1, which presents 13 earthquakes that occurred from the year 2000 onwards. All these deadly events except one took place in developed countries with poor standards of building construction. However, the populations that occupy buildings have various characteristics in different countries and regions, which may play a crucial part in enhancing or impeding vulnerability to earthquakes, ultimately influencing the number of casualties in a given event. These nonstructural variables include individual characteristics, such as gender, age, physical disabilities and behavioral strategies; household characteristics, such as socioeconomic status (usually household income); and community characteristics, such as the existence of search and rescue teams and the medical aid response.

Evidence from other natural events such as floods suggests that communities with socially vulnerable populations experience more casualties (Cutter et al. 2003; Zahran et al. 2008). In light of recent events such as the 2010 Haiti earthquake, this finding should be investigated in the specific context of earthquake loss estimation and casualty modeling. This paper reviews the state of knowledge of epidemiological and engineering research regarding earthquake-induced casualty assessment and proposes a theoretical framework to combine these two approaches. The potential influence of demographic and socioeconomic parameters is presented and assessed in terms of the vulnerability of the population and the relevance of their integration into engineering-based casualty estimation models, to combine a holistic approach with casualty assessment from earthquakes.

\section{Methods}

Three parallel literature reviews were conducted to examine: (1) the role of human factors, (2) the role of medical preparedness regarding earthquake-induced casualties, and (3) earthquake loss estimation models. Studies were identified through four computer-based literature search engines: PubMed/MEDLINE, Web of Science, Scopus and Google scholar (the last one in order to collect 'gray' literature). For all three topics of review, the year of publication was limited from January 1985 to March 2014, and only publications in English were included.

\subsection{Review of human factors and earthquake-induced injury and mortality}

Key words used to extract relevant articles were earthquake*, casualties*, injury*, death* and risk factors*. A total of 1042 abstracts were identified. Articles were included in this review if they focused on risk factors that were related to the previously mentioned human factors (i.e., individual and household characteristics) and used analytical designs (such as cross-sectional or case-control studies) that presented a quantified measure of the different 
risk factors (e.g., odds ratio or beta coefficient). Articles were excluded from this review if they had a descriptive design and did not present any measurable effect size (i.e., regression coefficient) or if it focused on casualties from other disastrous events rather than earthquakes or from earthquakes' secondary events (such as tsunami or landslides). These criteria used to screen all abstracts included. Thirteen studies met these criteria and were included in this section (Shoaf et al. 1998; Mahue-Giangreco et al. 2001; (Liang et al. 2001; Peek-Asa et al. 2003; Chou et al. 2004; Doocy et al. 2009, 2013; Ellidokuz et al. 2005; Dong et al. 2012; Kolbe et al. 2010; Osaki and Minowa 2001; Roces et al. 1992; Armenian et al. 1992). The steps of the literature review are described in Fig. 2. The covariates examined in each study and their effect estimates were identified.

\subsection{Review of medical preparedness and earthquake-induced injury and mortality}

Key words used to extract relevant articles were earthquake, casualties, * injury*, death*, rate*, risk factors*, preparedness* and medical care*. A total of 1050 abstracts were identified. Studies were eligible for inclusion if they specifically measured the association between receiving medical aid or preparedness of medical responders in hospital or prehospital settings and mortality or injury rates after an earthquake, and if they presented measurable results of this association (i.e., regression coefficient or difference in casualty rates). Studies were excluded from this section if they did not present any measurable results or if focused on casualties from other disastrous events rather than earthquakes or from earthquakes' secondary events (such as tsunami or landslides). These criteria used to screen all abstracts included. Eight studies met these criteria and were included in this section (Noji et al. 1993; Pretto et al. 1994; Tanaka et al. 1998; Fawcett and Oliveira 2000; Liang et al. 2001; Bissell et al. 2004; Jiang et al. 2012; Wen et al. 2012). Several additional

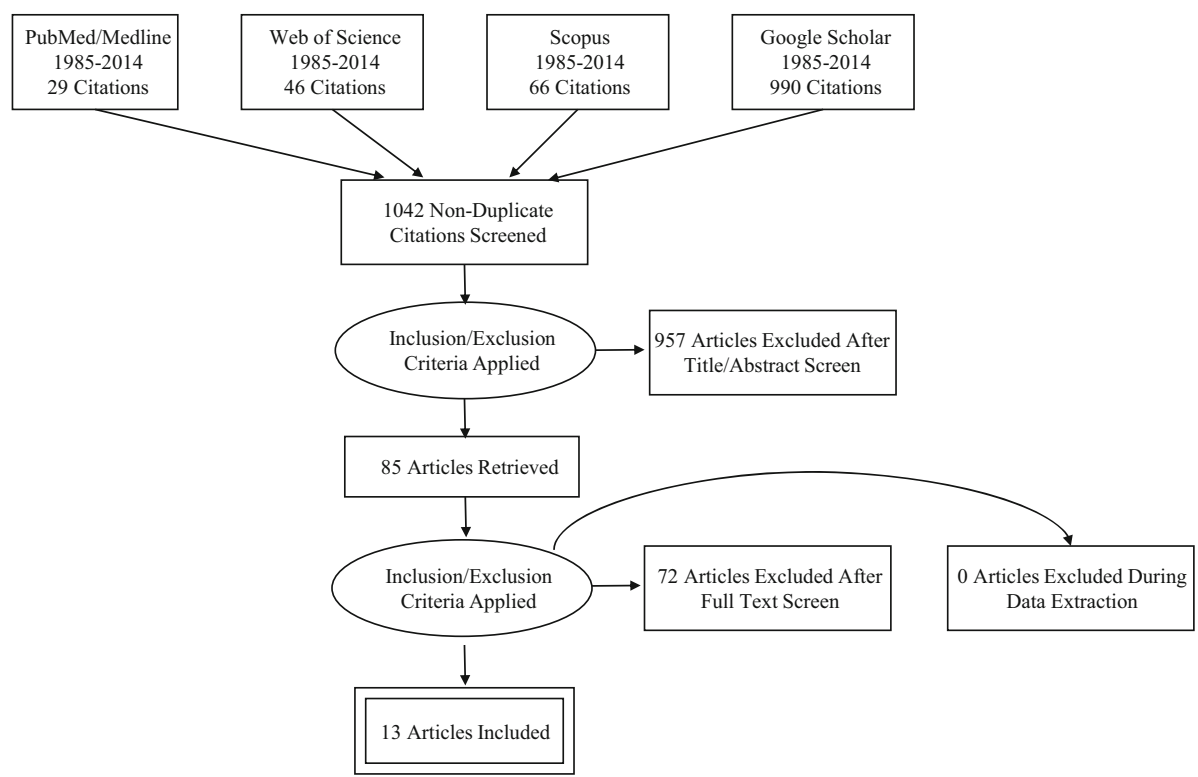

Fig. 2 Flow chart of the literature review 'human factors and earthquake-induced injury and mortality' 
studies were included in this section for the purpose of establishing a theoretical framework for the association between medical preparedness and response and the number of casualties in earthquake events (Schultz et al. 1996; Peek-Asa et al. 1998; Ashkenazi et al. 2005; Ramirez and Peek-Asa 2005; Macintyre et al. 2006; Bayard 2010; Bartal et al. 2011; Haojun et al. 2011; Archer et al. 2011). Although these studies did not quantitatively measure the association between medical preparedness and response and earthquake casualties, they contributed through establishing the need for evidence-based and theoretically driven modeling. Summaries of 14 articles with analytical designs $(n=14)$ that were included in the first two sections are presented in Table 1.

\subsection{Review of earthquake casualty assessment methods and models}

This section describes a state-of-the-art review of earthquake engineering-based casualty models currently in use around the world. Key words used to extract relevant data were earthquake*, seismic hazard*, casualty*, estimation*, assessment*, engineering*, model* and approach*. A total of 70 studies were identified, of which seven that represented the four common approaches in engineering-based casualty estimation (Maqsood and Schwarz 2011) were chosen (Samadjieva and Badel 2002; Porter et al. 2008; Jaiswal and Wald 2010a, b; Jaiswal et al. 2011; Spence and So 2009; FEMA 2003). Special emphasis was given to the HAZUS-MH loss estimation model since it is considered the 'state of the art' model in this field, currently used not only in the USA, but also around the world (Menezes and Inyang 2012).

\section{Results}

The majority of epidemiological studies were from regions with well-developed health infrastructures, such as the USA, Taiwan, Armenia, Turkey and Japan. Several recent studies focusing on the 2010 Haiti earthquake were found, but many regions with high earthquake incidence and casualties do not have published studies in the research literature (e.g., Pakistan, Sumatra).

\subsection{Individual and household characteristics and earthquake-induced injury and death}

Studies that examined the effects of gender had conflicting results, finding either no difference by gender or a higher rate of casualties among women. Studies from the USA, Taiwan, Turkey and Haiti found no differences in the risk of injury and death by gender (Mahue-Giangreco et al. 2001; Liang et al. 2001; Ellidokuz et al. 2005; Doocy et al. 2013). Among the four studies that found women at higher risk of injury and death, two from the USA (Shoaf et al. 1998; Peek-Asa et al. 2003) had the highest odds ratios (OR) for increased risk of injury of 1.64 (95\% CI N/A) and 2.4 (95\% CI 1.2, 5.1), respectively. Studies from Taiwan and Peru found women to be at higher risk of injury (Doocy et al. 2009) and death (Chou et al. 2004), but with smaller odds ratios: OR 1.2 (95 \% CI 1.1, 1.3) and OR 1.6 (95\% CI 1.0, 2.7), respectively. The USA and Taiwan had conflicting findings, with studies in both regions reporting increased risk of females and no significant differences related to gender regarding the same earthquake events. 


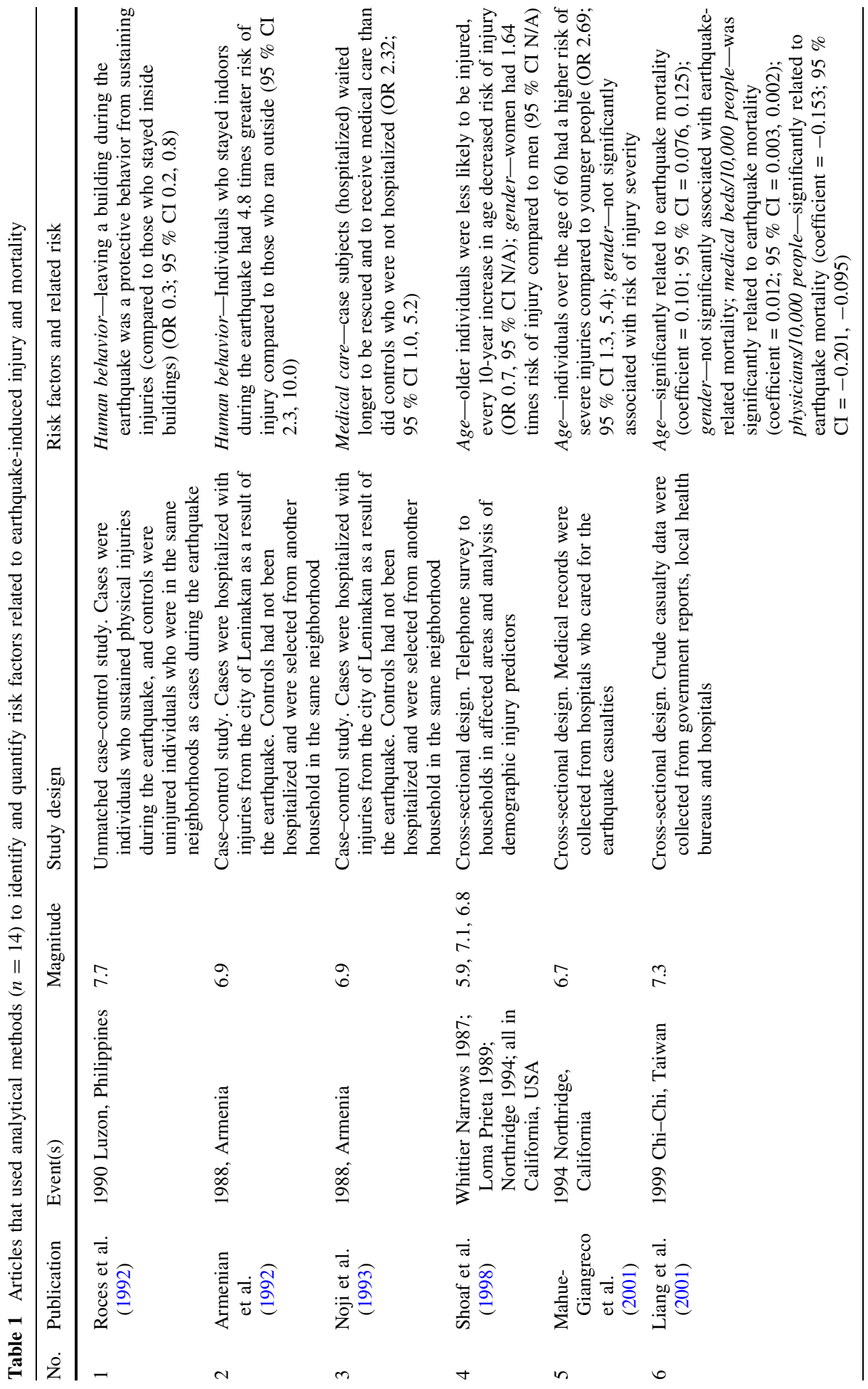




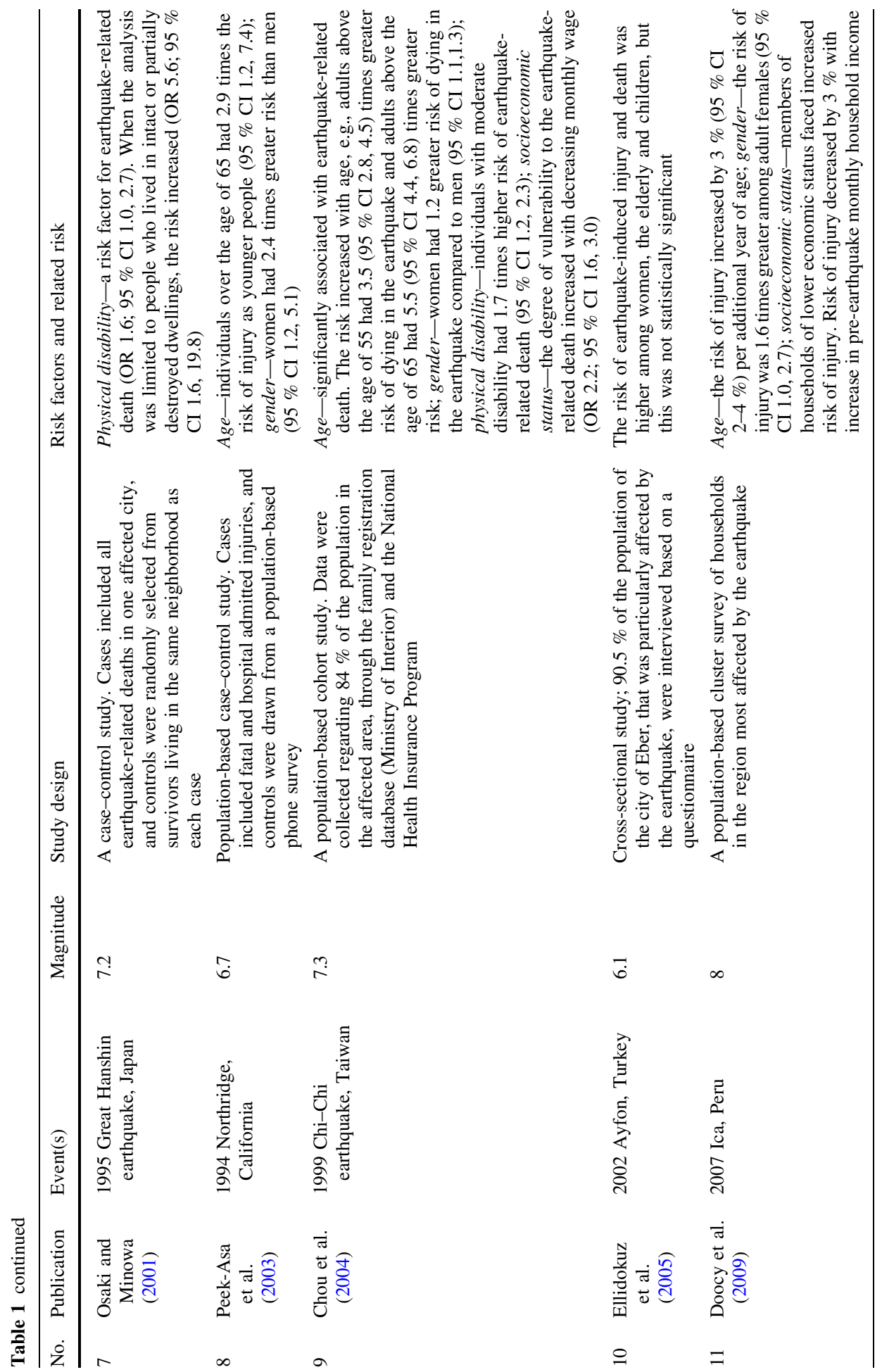




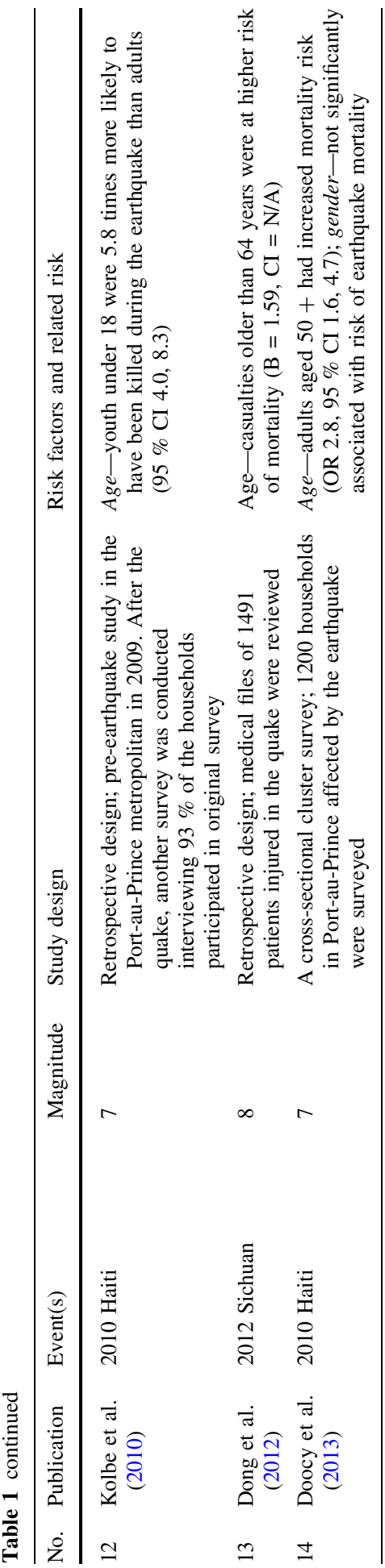

Springer 
Studies that examined age had inconsistencies, but reported some common results. Those spanning 25 years and a variety of geographic regions found higher rates of casualties among the elderly and children. One exception was a study from the USA that reported decreased risk of earthquake-induced injury with increasing age (OR 0.7, $95 \% \mathrm{CI}$ N/A) (Shoaf et al. 1998). Among the seven studies that found the elderly to be at higher risk for injury and death, Chou et al. from Taiwan (2004) had the highest odds ratio for increased risk of death of 5.5 (95\% CI 4.4, 6.8). Three studies from the USA and Haiti (Mahue-Giangreco et al. 2001; Peek-Asa et al. 2003; Doocy et al. 2013) found lower odds ratios of increased risk of injury OR 2.69 (95\% CI 1.34, 5.4), OR 2.9 (95\% CI 1.2, 7.4) and increased risk of death OR 2.8 (95\% CI 1.66, 4.72), respectively. Two other studies from Taiwan and China (Liang et al. 2001; Dong et al. 2012) also found age to be significantly associated with higher mortality and reported coefficient value of $0.101(95 \%$ CI $0.076,0.125$ ) and B coefficient of 1.539 (95\% CI N/A). A study from Peru (Doocy et al. 2009) did not report odds ratio or coefficient values, but stated that increases in age increased the risk of injury by $3 \%(95 \%$ CI 2, 4).

Studies from the USA reported conflicting findings, with studies regarding the same event reporting that the elderly were at higher risk of injury and death and that increased age lowered risk. Studies from Haiti (Kolbe et al. 2010) and Taiwan (Chou et al. 2004) found children to be at higher risk of death, and both reported similar odds ratios of 5.8 (95\% CI 4, 8.3) and 5.5 (95\% CI 4.4, 6.8), respectively.

Although many articles discussed the role of poverty and socioeconomic status on earthquake casualties, few measured the risks related to these factors (Cannon 1994; Fothergill and Peek 2004; Kahn 2005). Figure 1 demonstrates that most deadly earthquakes occur in developing countries rather than in developed countries, but even when an earthquake strikes a well-developed country such as the USA, there is evidence that lowincome households were more affected than high-income households (Fothergill and Peek 2004). However, studies from Taiwan (Chou et al. 2004) and Peru (Doocy et al. 2009) used analytical methods to measure the role of socioeconomic status as a risk factor for earthquake-related injury and death. The Taiwanese study found that the degree of vulnerability to earthquake-related death increased with decreasing monthly wage (OR 2.2, $95 \%$ CI 1.6, 3.0). Similarly, the study from Peru found that members of households with lower economic status faced increased risk of injury and that the risk decreased by $3 \%$ per additional 100 soles (Peruvian currency) of monthly household income (Doocy et al. 2009).

Only two studies directly assessed the link between physical disability and the risk of earthquake-induced death; both found a higher rate of casualties among physically disabled individuals. The Japanese study (Osaki and Minowa 2001) found an odds ratio of 1.9 (95\% CI 1.0, 3.4), and similarly, the study from Taiwan (Chou et al. 2004) found an odds ratio of 1.7 (95\% CI 1.2, 2.3).

Two studies examined the effect of human behavior during an earthquake on the risk of injury and death and found that exiting the building decreased the risk of injury and death. The first study, from the Philippines (Roces et al. 1992), found a lower odds ratio for injury (OR 0.3; $95 \%$ CI 0.1, 0.9) among subjects who were outside buildings. Similarly, a study from Armenia (Armenian et al. 1992) found a higher odds ratio for injury (OR 4.8; $95 \%$ CI 2.34, 10.0) among subjects who remained inside.

Ethnicity was discussed in American studies and was found a significant risk factor affecting injury and death in earthquakes (Shoaf et al. 1998; Mahue-Giangreco et al. 2001), although not consistently. Since ethnic groups and their characteristics vary from region to region, this issue is not addressed here. 


\subsection{Medical preparedness and earthquake-induced injury and mortality}

A large earthquake is likely to incur mass casualties. This has several implications for the local health system in both pre-hospital and hospital settings and on the aftermath of the event. Many studies have determined that rapid extrication of victims trapped under rubble significantly reduces mortality in earthquakes. The victims tend to have typical injuries (e.g., crush syndrome), which require knowledge of appropriate treatment methods (Schultz et al. 1996; PeekAsa et al. 1998; Ashkenzai et al. 2005; Ramirez and Peek-Asa 2005; Macintyre et al. 2006; Bartal et al. 2011). Therefore, the existence and efficacy of search and rescue teams combined with access to pre-hospital care may have a crucial effect on the number casualties (Haojun et al. 2011). Local hospitals, which are expected to provide care for the victims, may be overwhelmed by the large number of casualties arriving in a short period. In addition, providing medical aid in a disaster-affected area also entails working under extreme conditions, such as reduced workforce, limited medical supplies and resources compared to the increased demands for medical care (Archer et al. 2011; Jiang et al. 2012), and requires particular knowledge and preparedness for this scenario. Nonetheless, hospitals are considered the principal providers of immediate medical care after catastrophic events, and the general assumption is that a wellprepared hospital and medical staff could reduce mortality after a serious earthquake (Schultz et al. 1996; Pretto et al. 1994). Only one study directly assessed health sector preparedness levels and the association with earthquake-induced mortality. The findings revealed that 'low prepared' regions had five times more fatalities per 100 injuries compared to 'medium prepared' regions and that 'high prepared' regions had 30 times fewer fatalities compared to 'medium prepared' regions (Bissell et al. 2004). Other studies found that the mortality rate for severely injured victims was 15-25\% and was usually higher in frontline hospitals and that these rates may decline to 9-3\% or even lower, if proper medical care is not delayed (Pretto et al. 1994; Tanaka et al. 1998; Fawcett and Oliveira 2000; Jiang et al. 2012; Wen et al. 2012). Some studies reported findings that relate to this subject indirectly. An Armenian study found that subjects who were severely injured in an earthquake waited longer to receive medical care compared with subjects who with mild injuries (OR 2.32; 95 \% CI 1.0, 5.2) (Noji et al. 1993). Another study from Taiwan reported that the number of available hospital beds (coefficient value 0.012; $95 \% \mathrm{CI} 0.003,0.022$ ) and the rate of doctors per 10,000 people (coefficient value $-0.153 ; 95 \%$ $\mathrm{CI}-0.210,-0.095)$ affected the risk of mortality among the population exposed to an earthquake (Liang et al. 2001). Furthermore, complications such as gangrene, sepsis and disabilities due to delayed medical care were reported after the 2010 Haiti earthquake (Bayard 2010).

\subsection{Earthquake casualty assessment models}

Four approaches are often used to estimate casualties in earthquakes (Maqsood and Schwarz 2011). The empirical approach consists of directly correlating the magnitude/intensity of the earthquake and the size of the population in the area at times of the earthquake, based on historic earthquake statistics (Samadjieva and Badel 2002; Jaiswal and Wald 2010a). The semiempirical approach builds on the empirical approach by additionally accounting for the types of buildings that characterize the area and damage rates according to the different structures (Jaiswal and Wald 2010b). The purely analytic approach predicts behavior of buildings and their effects on individuals inside them, based on seismic hazard analysis (Porter et al. 2008; Spence and So 2009). An expansion of the other approaches that include all the aforementioned parameters and consider the population distribution in various occupancies and time frames, e.g., day, night and commute time, has been proposed (FEMA 2003). 
In regions that have experienced numerous earthquakes with high numbers of fatalities, typically developing countries with dense populations living in vulnerable structures, enough data exist to calibrate fatalities from the historical earthquake record alone (FEMA 2008). In such regions, building inventories are typically lacking, as are systematic analyses of their vulnerabilities; hence, analytical tools are inadequate for loss estimation. In contrast, in the most highly developed countries, particularly those with substantive building codes, structural responses are more easily analyzed and information on their distribution and occupancy is more readily available ( $\mathrm{Li}$ et al. 2011; Jaiswal and Wald 2010a). Due to the success of such building codes, for the purpose of fatality loss modeling, this category of countries typically has had relatively few fatal earthquakes, making it difficult to use empirical calibration from past events alone. In such cases, fatality estimates are largely informed from analytically derived collapse rates and inferred fatality ratios given a structural collapse (Jaiswal et al. 2011; Jaiswal and Wald 2010a, b). The last approach is applied in the HAZUS-MH loss estimation model (FEMA 2003), which is an American loss estimation methodology that can be utilized globally in different countries and regions. In HAZUS-MH, casualties are calculated as a function of building damage for given ground accelerations. Some demographic data such as age, ethnicity and household income are entered into the database, but these data are used only for estimating the expected displaced population and shelter needs and not to calculate casualties. Factors such as gender, disability and expected behavior during earthquakes are not taken into account in the current methodology. Medical preparedness and response is also a factor which is not considered at this time (FEMA 2003). Table 2 summarizes the information in

Table 2 Demographic and socioeconomic factors used by the HAZUS-MH social loss modules to estimate the rate of casualties and displaced population

\begin{tabular}{|c|c|c|c|}
\hline & $\begin{array}{l}\text { Casualty } \\
\text { rate } \\
\text { estimation }\end{array}$ & $\begin{array}{l}\text { Displaced } \\
\text { population } \\
\text { estimation }\end{array}$ & Publications addressing this issue \\
\hline Age & - & + & $\begin{array}{l}N=9 \\
\text { Shoaf et al. (1998), Mahue-Giangreco et al. (2001), Liang } \\
\text { et al. (2001), Peek-Asa et al. (2003), Chou et al. (2004), } \\
\text { Doocy et al. (2009), Kolbe et al. (2010), Doocy et al. } \\
\text { (2013), Dong et al. (2012) }\end{array}$ \\
\hline Gender & - & - & $\begin{array}{l}N=8 \\
\text { Shoaf et al. (1998), Mahue-Giangreco et al. (2001), Liang } \\
\text { et al. (2001), Peek-Asa et al. (2003), Chou et al. (2004), } \\
\text { Ellidokuz et al. (2005), Doocy et al. (2009), Doocy et al. } \\
\text { (2013) }\end{array}$ \\
\hline Ethnicity & - & + & $\begin{array}{l}N=2 \\
\text { Shoaf et al. (1998), Mahue-Giangreco et al. (2001) }\end{array}$ \\
\hline $\begin{array}{l}\text { Physical } \\
\text { Disability }\end{array}$ & - & - & $\begin{array}{l}N=2 \\
\text { Osaki and Minowa (2001), Chou et al. (2004) }\end{array}$ \\
\hline $\begin{array}{l}\text { Household } \\
\text { income }\end{array}$ & - & + & $\begin{array}{l}N=2 \\
\text { Chou et al. (2004), Doocy et al. (2009) }\end{array}$ \\
\hline $\begin{array}{l}\text { Behavior during } \\
\text { an earthquake }\end{array}$ & - & - & $\begin{array}{l}N=2 \\
\text { Roces et al. (1992), Armenian et al. (1992) }\end{array}$ \\
\hline $\begin{array}{l}\text { Medical } \\
\text { preparedness }\end{array}$ & - & - & $\begin{array}{l}N=1 \\
\text { Bissell et al. (2004) }\end{array}$ \\
\hline
\end{tabular}

+ Indicates a factor which is accounted for in the module

- Indicates a factor which is not accounted for in the module 
this section and emphasizes the gaps between the epidemiological and engineering approaches for earthquake-induced casualty estimations.

\section{Discussion}

Despite increasing efforts to prepare for and mitigate the effects of earthquakes, they cannot be predicted and continue to cause loss of human life, severe disability and property damage. Recent events in China (2008), Haiti (2010) and Japan (2011) have illustrated the difference between earthquakes that occur in developing countries compared to those in developed countries. When examining these events, the size of the earthquake (amount of energy released) and other microseismic characteristics have limited influence on casualties, indicating that other parameters related to the characteristics of the exposed population may play a key role in outcomes.

The concept of vulnerability in the natural hazard field embraces physical, social, economic and environmental dimensions (Smith 2013). Modern casualty estimation models are based mainly on the vulnerability of the built environment and its performance under different ground accelerations (FEMA 2003). However, a gap exists between factors described in the literature as increasing the risk of earthquake-induced injury and death and the factors considered in these models. The present study revealed that population characteristics, such as gender and age distribution, a physical disability, socioeconomic status, and human behavior during the event, affected the choice of protective strategy, all of which have a crucial influence on the number of casualties from a given event. These factors have been documented in descriptive reports after earthquakes throughout history and were significant in the analytical studies reviewed here. However, these factors have different effects in different earthquakes and could be important interaction variables with seismic and built-environment factors. Predictors are likely to be highly interactive and varied based on the parameters of the earthquake and its location. For example, increased risk of death among the elderly and those with disabilities could be tied both to the types of structures and to the types of behaviors-such as an inability to evacuate the building (Peek-Asa et al. 2003; Chou et al. 2004). However, these factors that represent human vulnerability to disasters are not currently integrated in casualty estimation models, a fact that can alter the outcomes of the risk assessment and management. The concept of human vulnerability to disasters refers to social and economic fragility, lack of social resilience and abilities to cope. Vulnerability (among other-human vulnerability) is considered a key factor determining the potential risk from a given hazard. Interacting with the amount of exposure to a hazard and the extant of capacity measures (e.g., medical preparedness and response), it affects the consequences of disastrous events worldwide (Birkmann, 2006). Therefore, human vulnerability assessment serves as a tool for effective risk assessment in terms of the expected number of casualties in a future event and also as a measure of disaster risk reduction achieved by empowering vulnerable populations (UNISDR 2014).

Furthermore, in most emergency plans, hospital and staff preparedness are assumed important in mitigating the number of casualties and injury severity (Barbera et al. 2009). Great efforts are invested to improve the level of preparedness among healthcare facilities and staff in order to obtain the appropriate response to future events, primarily manifested by increasing knowledge and improving the ability to provide adequate care as quickly as possible (Ben Natan et al. 2013). These efforts, as suggested from the studies reviewed in this work, may reduce the 
mortality rates of critically injured individuals by tens of percent. This increases the need to evaluate the level of medical preparedness in different regions and to apply the findings when estimating casualties or planning disaster responses for future events. Another issue related to casualty rates and to the delay in providing medical aid is disruption to transportation infrastructure as a result of an earthquake, which may cause roadway-related injuries and hamper efforts to evacuate casualties to hospitals (Schultz, et al. 1996; Chan et al. 2006; Wang et al. 2009). This issue was not addressed in this current study, but needs to be investigated and considered further when planning for an earthquake scenario.

Despite the lack of population and behavioral factors in casualty prediction models, some of these factors are considered when predicting the size of displaced populations (i.e., requiring shelter) in the HAZUS loss estimation model. Integrating population and behavioral characteristics into loss estimation models could use similar methods as those that predict population displacement, thereby improving the accuracy of loss prediction models and providing better integration with displacement models.

\section{Limitations}

The process of predicting casualties in future earthquake events is highly complex and involves factors such as robustness of critical infrastructures, which were not considered in this study. The number of studies that used analytical methods to determine the risk factors related to the characteristics of the affected population and to medical preparedness is relatively low and disproportionately represented in regions with developed infrastructures. These results may not be directly generalizable to all earthquakes, but the body of evidence strongly supports the need to integrate population characteristics into prediction models for all regions.

\section{Conclusions}

This study provides evidence that integrates demographic and socioeconomic characteristics and levels of medical preparedness into existing casualty estimation models may refine the predicted outcomes and improve earthquake casualty estimation accuracy. In order to enhance preparedness and mitigate dire outcomes of future earthquakes, countries and regions depend on predictions and estimations of damage and casualties that are generated by loss estimation models. Hence, it is very important to estimate casualties as accurately as possible. This is a difficult and complex task, which requires considering many factors and therefore benefits by involving different disciplines (e.g., epidemiology and engineering). Public health agencies and other community or national organizations may consider using this information to allocate resources more adequately to enhance preparedness and mitigate future loss among vulnerable population groups.

Acknowledgments The authors thank the Israeli Ministry of Science, Technology and Space and the National Steering Committee for earthquake preparedness for their support in this research.

Conflict of interest The authors declare that they have no conflict of interests.

Open Access This article is distributed under the terms of the Creative Commons Attribution 4.0 International License (http://creativecommons.org/licenses/by/4.0/), which permits unrestricted use, distribution, and reproduction in any medium, provided you give appropriate credit to the original author(s) and the source, provide a link to the Creative Commons license, and indicate if changes were made. 


\section{References}

Alexander D (1985) Death and injury in earthquakes. Disasters 9:57-60

Archer N, Moschvis PP, Le PV, Farmer P (2011) Perspective: postearthquake Haiti renews the call for global health training in medical education. Acad Med 86:889-891

Armenian HK, Noji EK, Oganesian AP (1992) A case-control study of injuries arising from the earthquake in Armenia, 1988. Bull World Health Organ 70:251-257

Ashkenzai I, Isakovich B, Kluger Y, Alfici R, Kessel B, Better OS (2005) Prehospital management of earthquake casualties buried under rubble. Prehosp Disaster Med 20:122-133

Barbera JA, Yeatts DJ, Macintyre AG (2009) Challenges of hospital emergency preparedness: analysis and recommendations. Disaster Med Public Health Prep 3(S1):S74-S82

Bartal C, Zeller L, Miskin I, Sebbag G, Karp E, Grossman A, Engel A, Carter D, Kreiss Y (2011) Crush syndrome: saving more lives in disasters, lessons learned from the early-response phase in Haiti. Arch Intern Med 171:694-696

Bayard D (2010) Haiti earthquake relief, phase two: long-term needs and local resources. New Engl J Med 360:1858-1861

Ben Natan M, Nigel S, Yevdayev I, Qadan M, Dudkiewicz M (2013) Nurse willingness to report for work in the event of an earthquake in Israel. J Nurs Manag 22(7):931-939

Birkmann J (2006) Measuring vulnerability to promote disaster-resilient societies: conceptual frameworks and definitions. In: Birkmann J (ed) Measuring vulnerability to natural hazards: towards disaster resilient societies. United Nations University Press, Tokyo, pp 9-54

Bissell RA, Pinet L, Nelson M, Levy M (2004) Evidence of the effectiveness of health sector preparedness in disaster response, the example of four earthquakes. Fam Community Health 27:193-203

Cannon T (1994) Vulnerability analysis and the explanation of 'natural' disasters. In: Varely A (ed) Disasters, development and environment. Wiley, London, pp 13-30

Chan YF, Alagappan K, Gandhi A, Donovan C, Tewari M, Zaets SB (2006) Disaster management following the Chi-Chi earthquake in Taiwan. Prehosp Disaster Med 21:196-202

Chou YJ, Huang N, Lee CH, Tsai SL, Chen LS, Chang HJ (2004) Who is at risk of death in an earthquake? Am J Epidemiol 160:688-695

Crowley K, Elliott JR (2012) Earthquake disasters and resilience in the global North: lessons from New Zealand and Japan. Geogr J 178:208-215

Cutter SL, Boruff BJ, Shirley WL (2003) Social vulnerability to environmental hazards. Soc Sci Q $84: 242-261$

Dong ZH, Yang ZG, Chu ZG, Chen TW, Bai HL, Shao H, Tsang SS, Denor JC (2012) Earthquake-related injuries: evaluation with multidetector computed tomography and digital radiography of 1491 patients. J Crit Care 27:103.e1-103.e6

Donner W, Rodriguez H (2008) Population composition, migration and inequality: the influence of demographic changes on disaster risk and vulnerability. Soc Forces 87:1089-1114

Doocy S, Daniels A, Aspilcueta D (2009) Mortality and injury following the 2007 Ica earthquake in Peru. Am J Disaster Med 4:15-22

Doocy S, Cherewick M, Kirsch T (2013) Mortality following the Haitian earthquake of 2010: a stratified cluster survey. Popul Health Metr 11:5

Ellidokuz H, Ucku R, Aydin UY, Ellidokuz E (2005) Risk factors for death and injuries in earthquake: cross-sectional study from Afyon, Turkey. Croat Med J 46:613-618

EM-DAT (2014) The international disaster database. http://www.emdat.be/database. Accessed 10 Jan 2014

Fawcett W, Oliveira CS (2000) Casualty treatment after earthquake disasters: development of a regional simulation model. Disasters 24:271-287

FEMA (2003) HAZUS-MH MR4 technical manual

FEMA (2008) HAZUS MH estimated annualized earthquake losses for the United States. Federal Emergency Management Agency

Fothergill A, Peek LA (2004) Poverty and disasters in the United States: a review of recent sociological findings. Nat Hazards 32:89-110

Haojun F, Jianqi S, Shike H (2011) Retrospective, analytical study of field first aid following the Wenchuan earthquake in China. Prehosp Disaster Med 26:130-134

Jaiswal KM, Wald D (2010a) An empirical model for global earthquake fatality estimation. Earthq Spectra 26:1017-1037

Jaiswal KS, Wald DJ (2010b) Development of semi-empirical loss model within the USGS prompt assessment of global earthquake response (PAGER) system. Canada, Toronto, pp 1-12 
Jaiswal KS, Wald DJ, Hearne M (2009) Estimating casualties for large earthquakes worldwide using an empirical approach. US Geological Survey Open File Report 2009-1136

Jaiswal K, Wald D, D’Ayala D (2011) Developing empirical collapse fragility functions for global building types. Earthq Spectra 27:775-795

Jiang J, Li Y, Huang X, Li B, Su L, Zhong D, Shi C, Li M, Shan J, Chen Y (2012) Lessons learnt from the Wenchuan earthquake: performance evaluation of treatment of critical injuries in hardest-hit areas. J Evid Based Med 5(3):114-123

Kahn ME (2005) The death toll from natural disasters: the roll of income, geography and institutions. Rev Econ Stat 87:271-284

Kolbe AR, Hutson RA, Shannon H, Trzcinski E, Miles B, Levitz N, Puccio M, James L, Noel JR, Muggah R (2010) Mortality, crime and access to basic needs before and after the Haiti earthquake: a random survey of Port-au-Prince households. Med Confl Surviv 26:281-297

Li Y, Wu Z, Zaho Y (2011) Estimating the number of casualties in earthquakes from early field reports and improving the estimate with time. Nat Hazards 56:699-708

Liang NJ, Shih YT, Shih FY, Wu HM, Wang HJ, Shi SF, Liu MY, Wang BB (2001) Disaster epidemiology and medical response in the Chi-Chi earthquake in Taiwan. Ann Emerg Med 38:549-555

Macintyre AG, Barbera JA, Smith E (2006) Surviving collapsed structure entrapment after earthquakes: a "time-to-rescue" analysis. Prehosp Disaster Med 21:4-17

Mahue-Giangreco M, Mack W, Seligson H, Bourque L (2001) Risk factors associated with moderate and serious injuries attributable to the 1994 Northridge earthquake, Los Angeles, California. Ann Epidemiol 11:347-357

Maqsood ST, Schwarz J (2011) Estimation of human casualties from earthquakes in Pakistan an engineering approach. Seismol Res Lett 82:32-41

Menezes GB, Inyang HI (2012) Linking HAZUS-MH risk-analysis methodology to contaminant-release models. Nat Hazards Rev 13:74-81

Noji EK, Kelen GD (1990) The 1988 earthquake in Soviet Armenia: a case study. Ann Emerg Med 19:891-987

Noji EK, Armenian HK, Oganessian A (1993) Issues of rescue and medical care following the 1988 Armenian earthquake. Int J Epidemiol 22:1070-1076

Osaki Y, Minowa M (2001) Factors associated with earthquake deaths in the great Hanshin-Awaji earthquake, 1995. Am J Epidemiol 153:153-156

Paton D, Bajek R, Okada N, McIvor D (2010) Predicting community earthquake preparedness: a crosscultural comparison of Japan and New Zealand. Nat Hazards 54:765-781

Peek-Asa C, Kraus JF, Bourque LB, Vimalachandra D, Yu J, Abrams J (1998) Fatal and hospitalized injuries resulting from the 1994 Northridge earthquake. Int J Epidemiol 27:459-465

Peek-Asa C, Ramirez M, Seligson H, Shoaf K (2003) Seismic, structural, and individual factors associated with earthquake related injury. Int Prev 9:62-66

Porter K, Jaiswal KS, Wald DJ, Earle PS, Hearne M (2008) Fatality models for the US geological survey's prompt assessment of global earthquake for response (PAGER) system. In: Proceedings of the 14th world conference on earthquake engineering, 12-17 Oct, Beijing

Pretto EA, Angus DC, Abrams JI, Shen B, Bissell R, Ruiz Castro VM, Sawyers R, Watoh Y, Ceciliano N, Ricci E (1994) An analysis of prehospital mortality in an earthquake. Prehosp Disaster Med 9:107-117

Ramirez M, Peek-Asa C (2005) Epidemiology of traumatic injuries from earthquakes. Epidemiol Rev 27:47-55

Roces MC, White ME, Dayrit MM, Durkin ME (1992) Risk factors for injuries due to the 1990 earthquake in Luzon, Philippines. Bull World Health Organ 70:509-514

Samadjieva E, Badel J (2002) Estimation of the expected number of casualties caused by strong earthquakes. Bull Seismol Soc Am 92:2310-2322

Schultz CH, Koenig KL, Noji EK (1996) A medical disaster response to reduce immediate mortality after an earthquake. N Engl J Med 334:438-444

Shoaf KI, Sareen HR, Nguyen LH, Bourque LB (1998) Injuries as a result of California earthquakes in the past decade. Disasters 22:218-235

Smith K (2013) Complexity, sustainability and vulnerability. Environmental hazards: assessing risk and reducing disaster, 6th edn. Routledge, New York, pp 46-61

Spence R, So E (2009) Estimating shaking induced casualties and building damage for global earthquake events. NEHRP Grant. Final technical report. Cambridge Architectural Research, Ltd

Spence R, Bommer J, Del Re D, Bird J, Aydinoglu N, Tabuchi S (2003) Comparing loss estimation with observed damage a study of the 1990 Kocaeli earthquake in Turkey. Bull Earthq Eng 1:83-113

Tanaka H, Iwai A, Oda J, Kuwagata Y, Matsuoka T, Shimazu T, Yoshioka T (1998) Overview of evacuation and transport of patients following the 1995 Hanshin-Awaji Earthquake. J Emerg Med 16:439-444 
Tekeli-Yesil S (2006) Public health and natural disasters: disaster preparedness and response in health system. J Public Health 14:317-324

UNISDR (2014) Progress and challenges in disaster risk reduction: a contribution towards the development of policy indicators for the post-2015 framework on disaster risk reduction. The United Nations Office for Disaster Risk Reduction (UNISDR)

Wald D, Jaiswal K, Marano K, Earle P, Allen T (2011) Advancements in casualty modeling facilitated by the USGS prompt assessment of global earthquakes for response (PAGER) system. In: Spence R, So E, Scawthorn C (eds) Human casualties in earthquakes, progress in modelling and mitigation. Springer, Netherlands, pp 221-230

Wang F, Cheng Q, Highland L, Miyajima M, Wang H, Yan C (2009) Preliminary investigation of some large landslides triggered by the 2008 Wenchuan earthquake, Sichuan Province, China. Landslides 7:47-54

Wen J, Sun X, Shi YK, Li YP, Zhao LP, Wu Q, Fei YH (2012) Patient influx and trauma types in a front-line hospital and a secondary referral hospital after the Wenchuan earthquake: a retrospectively comparative study. Eur J Trauma Emerg Surg 38:261-267

Zahran S, Brody SD, Peacock WG, Vedlitz A, Grover H (2008) Social vulnerability and the natural and built environment: a model of flood casualties in Texas. Disasters 32:537-560 